\title{
Effect of heavy snowfall on ground temperature, northern Tibetan Plateau
}

\author{
Meixue YANG,${ }^{1,2,3}$ Tandong YAO, ${ }^{1,2}$ Xiaohua GOU, ${ }^{4}$ Huijun WANG ${ }^{3}$ \\ ${ }^{1}$ Laboratory of Cryosphere and Environment, Cold and Arid Regions Environmental and Engineering Research Institute, \\ Chinese Academy of Sciences, 260 Donggang West Road, Lanzhou 730000, China \\ E-mail: mxyang@ns.Izb.ac.cn \\ ${ }^{2}$ Institute of Tibetan Plateau Research, Chinese Academy of Sciences, Beijing 100101, China \\ ${ }^{3}$ The Nansen-Zhu International Research Center, Institute of Atmospheric Physics, Chinese Academy of Sciences, \\ Beijing 100101, China \\ ${ }^{4}$ Center for Arid Environment and Paleoclimate Research, College of Earth and Environment Sciences, Lanzhou University, \\ Lanzhou 730000, China
}

\begin{abstract}
Very heavy snowfall occurred in the Amdo-Nagqu region during winter 1997/98, and enormous numbers of sheep and yaks died due to starvation and low temperatures. Some observation sites of the GEWEX (Global Energy and Water Cycle Experiment) Asian Monsoon Experiment (GAME)Tibet are located in this area. In this paper, the variation of the ground temperature (GT) on the northern part of the Tibetan Plateau and its relationship with the heavy snow cover is analyzed based on the GAME-Tibet in situ observational data at several sites. The temporal and spatial differences of the variations of the daily maximum, daily minimum and range in GT are significant in 1997/98 in the northern part of the Tibetan Plateau. For example, at site D110, the daily range in GT fluctuated only $0.2^{\circ} \mathrm{C}$ from the end of December 1997 to mid-April 1998, but in the north, at site D66, the daily range in GT fluctuated between $5^{\circ} \mathrm{C}$ and $\sim 20^{\circ} \mathrm{C}$ at the same depth and during the same period. At the southernmost site, MS3637, the daily range in GT fluctuated within $1.0^{\circ} \mathrm{C}$ from mid-November to early February. From mid-February to mid-March, the daily range in GT increased and the peak was $8.1^{\circ} \mathrm{C}$. The temperature variation was related to the heavy snowfall that occurred on the northern Tibetan Plateau in winter 1997/98. The snow-cover conditions at different sites on the northern Tibetan Plateau were evaluated quantitatively from the variation of the GT at shallow depths.
\end{abstract}

\section{INTRODUCTION}

The water and energy cycles on the Tibetan Plateau are related to the variations in the Asian monsoon (Webster and others, 1998). Consequently, the uplifted land surface of the plateau, the anomaly of the area and duration of the snow cover influence the strength, onset and the end of the Asian monsoon (Barnett and others, 1989; Yasunari and others, 1991; Vernekar and others, 1995). The Tibetan Plateau has profound dynamic and thermodynamic effects on the general atmospheric circulation and climate in East Asia, and especially in China. Hahn and Manabe (1975) found that the Asian summer monsoon can be reasonably simulated only with the Tibetan Plateau topography incorporated into the GFL general circulation model. Wang (1984) and Wu and Zhang (1998) pointed out that the onset of the Asian monsoon depends to a large extent on the thermal effect of the plateau. Kuo and Qian (1982) found the topography of the Tibetan Plateau has a profound effect on the simulated precipitation pattern. Qian and others (1988, 2001, 2003) discovered important influences of the plateau on rainfall and the onset date of the monsoon.

The snow anomaly over the Tibetan Plateau changes its thermal forcing, remarkably influencing the development of the Asian monsoon, which, in turn, affects large-scale floods and droughts in China. It is thought that a positive snow anomaly on the plateau was one of the prime factors contributing to the 1998 severe floods in the Yangtze River basin and northeastern China (NCC of China, 1999; Chen, 2001).
Present-day measurements of temperature profiles in terrestrial boreholes have been used extensively to reconstruct the history of the ground surface temperature (GST) over a large range of spatial and temporal scales (Pollack and Smerdon, 2004). The borehole-based reconstructions of GST have been widely used as indicators of paleoclimate (Smerdon and others, 2004). These reconstructions assume that heat transport within the subsurface is purely conductive. Climatic interpretations of GST reconstructions also assume that GST is strongly coupled to surface air temperature (SAT) on timescales of decades and longer (Gosnold and others, 1997; Smerdon and others, 2004). Pollack and others (2005) have described a simple representation of this coupling in terms of variable thermal diffusivity in the upper meter of the subsurface. The variability was tied to daily SAT, precipitation and snow cover, but does not incorporate the physical details of these and the many other factors that influence the air-ground interface in many high-fidelity land surface models. Their simple model reduced the difference between observed and modeled temperatures by a factor of 3-4 over a model with uniform diffusivity driven only by SAT. Ground temperatures are generally warmer than air temperatures due to solar radiation effects in the summer and the insulating effect of snow cover during the winter. The low thermal diffusivity of snow dampens surface temperature variations; snow effectively insulates the ground during the coldest part of the year. A numerical model of snow-ground thermal interactions was developed by Bartlett and others (2004) to investigate the effect of seasonal snow cover on annual 


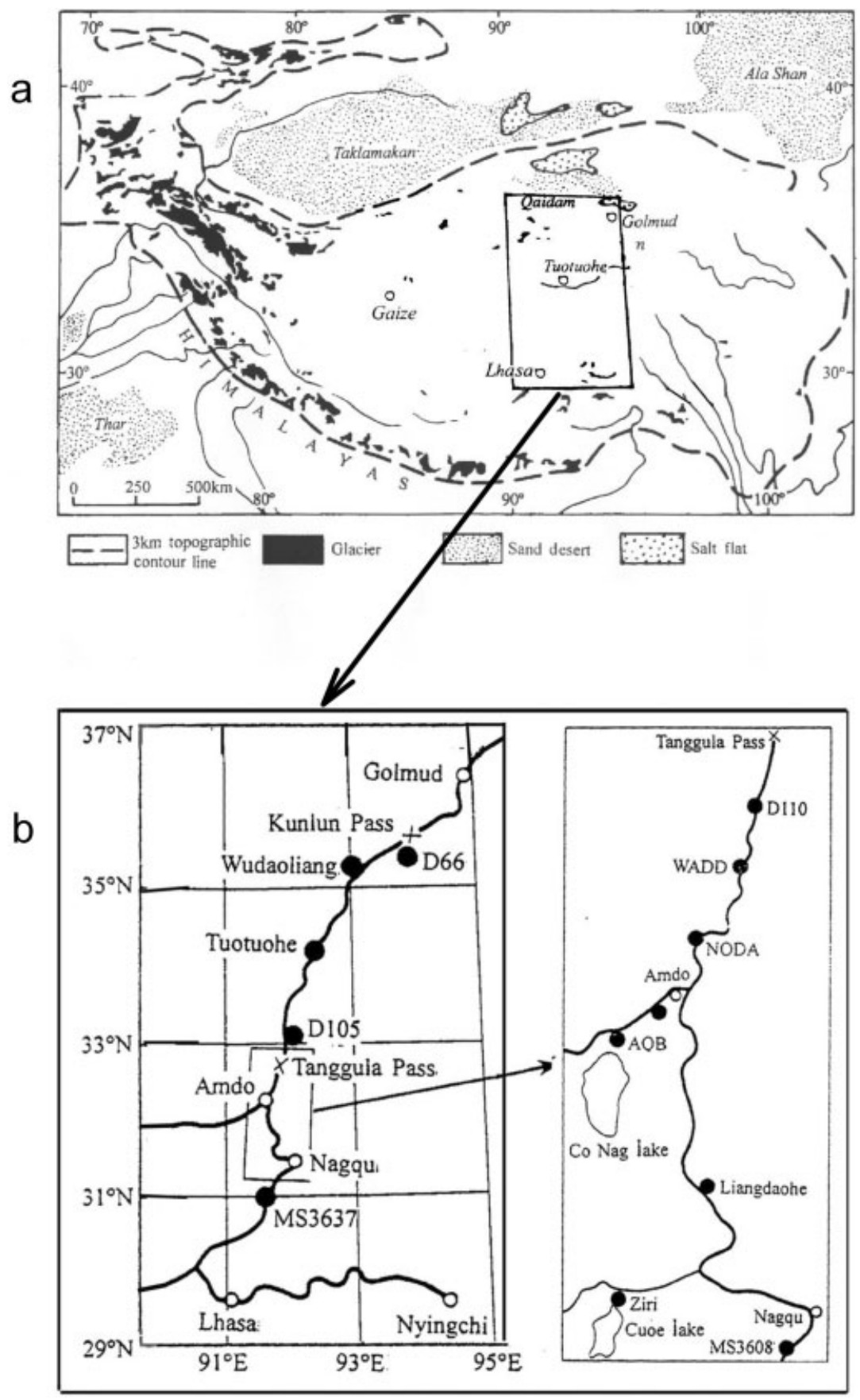

Fig. 1. Locations of the observation sites. (a) Map of the Qinghai-Xizang (Tibetan) Plateau with $3 \mathrm{~km}$ contour shown. The study area is outlined. (b) Enlarged maps of the study area. The right frame corresponds to the small square in the left frame. The solid lines represent roads and the filled circles represent observation sites.

ground temperatures. The model was parameterized in terms of three snow-event parameters: onset time of the annual snow event, duration of the event, and depth of snow during the event. The model was validated using SAT, subsurface temperature at $10 \mathrm{~cm}$ depth and snow-depth data from the 6 years of observations at Emigrant Pass climate observatory, northwestern Utah, USA, and 217 station years of US National Weather Service data from sites across North America. The measured subsurface temperature-time series was compared to changes predicted by the model. The model consistently predicted ground temperature changes that compared well with those observed. Sensitivity analysis of the model leads to a non-linear relationship between the three snow-event parameters (onset, duration and depth of the annual snow event) and the effect of snow on mean annual GST.

Beginning in 1996, a joint Chinese/Japanese GEWEX (Global Energy and Water Cycle Experiment) Asian Monsoon Experiment (GAME)-Tibet project has been carried out to investigate the effect of the Tibetan Plateau on the Asian monsoon system, to examine the interaction between land and atmosphere processes, and to improve the land surface parameterization scheme in climate models. The preliminary observation experiment was conducted from July to September 1997. During this period, the soil moisture and soil temperature measurement systems (SMTMS) and automatic weather stations were installed at several sites on the northern part of the Tibetan 
Table 1. Locations of observation sites

\begin{tabular}{|c|c|c|c|c|c|c|c|c|}
\hline & D66 & Tuotuohe & D110 & WADD & NODA & Amdo & MS3608 & MS3637 \\
\hline Latitude & $35^{\circ} 31.39^{\prime} \mathrm{N}$ & $34^{\circ} 13^{\prime} \mathrm{N}$ & $32^{\circ} 41.49^{\prime} \mathrm{N}$ & $32^{\circ} 33.07^{\prime} \mathrm{N}$ & $32^{\circ} 27.60^{\prime} \mathrm{N}$ & $32^{\circ} 14.47^{\prime} \mathrm{N}$ & $31^{\circ} 13.60^{\prime} \mathrm{N}$ & $31^{\circ} 01.05^{\prime} \mathrm{N}$ \\
\hline Longitude & $93^{\circ} 47.08^{\prime} \mathrm{E}$ & $96^{\circ} 26^{\prime} \mathrm{E}$ & $92^{\circ} 51.27^{\prime} \mathrm{E}$ & $91^{\circ} 48.05^{\prime} \mathrm{E}$ & $91^{\circ} 48.05^{\prime} \mathrm{E}$ & $91^{\circ} 37.51^{\prime} \mathrm{E}$ & $91^{\circ} 47.01^{\prime} \mathrm{E}$ & $91^{\circ} 39.42^{\prime} \mathrm{E}$ \\
\hline Elevation & $4560 \mathrm{~m}$ & $4533 \mathrm{~m}$ & $5000 \mathrm{~m}$ & $4850 \mathrm{~m}$ & $4850 \mathrm{~m}$ & $4710 \mathrm{~m}$ & $4610 \mathrm{~m}$ & $4650 \mathrm{~m}$ \\
\hline Surface type & Permafrost & Seasonally frozen & Permafrost & Permafrost & Permafrost & Seasonally frozen & Seasonally frozen & Seasonally frozen \\
\hline
\end{tabular}

Plateau. The intensive observation period of the GAMETibet project was conducted from May to September 1998.

In winter 1997/98, very heavy snowfall occurred on the Qinghai-Xizang (Tibetan) Plateau (Chen, 2001), especially in the Amdo-Nagqu region, resulting in the death of a large number of sheep and yaks due to starvation and low temperatures, putting enormous economic stress on local residents. Several GAME-Tibet observation sites are located within the heavy snowfall area. In this paper, we examine the effect of heavy snowfall on ground temperature variations using ground temperature data at different GAMETibet observation sites and analyze spatial and temporal variations of ground temperature during 1997/98.

\section{OBSERVATION SITES AND DATA COLLECTION}

\subsection{Observation sites}

The observation sites are located predominantly along the Qinghai-Tibet highway (Fig. 1). The site-specific geographic coordinates and elevations are listed in Table 1. Except for the northernmost site (D66), observations were conducted on grazing lands. To prevent damage by animals, the observation sites were enclosed by chain-linked fences. The height of vegetation generally does not vary from site to site, but vegetation density decreases northward.

\subsection{Data collection}

Each site was instrumented with a ground temperature observation system consisting of ten platinum temperature probes installed at depths of 4, 20,40,60, 80, 100, 130, 160 and $200 \mathrm{~cm}$ (the depth of the deepest probe varies from site to site) and connected to the data logger. Temperatures were measured at 1 hour intervals and automatically recorded. This paper mainly focuses on the variation of the daily maximum, minimum and range of the ground temperature.

\section{ANALYSIS AND RESULTS}

The ground temperature (GT) variation decreases with depth, especially for the daily range. Thus, we focus the discussion mainly on the temporal and spatial variation of the daily maximum, the daily minimum and the daily range in the shallowest layer $(4 \mathrm{~cm}$ depth).

\subsection{Variation of the daily maximum and minimum ground temperature at different sites}

The variations of the daily maximum and minimum GT at $4 \mathrm{~cm}$ depth (site D105 is $5 \mathrm{~cm}$ in depth) at different sites are shown in Figure 2. At site D66, the variation trends are consistent. The daily maximum GT fluctuates more than the daily minimum GT during summer, but the difference is not very marked. The temperature decrease during the period September-January is fundamentally consistent with the temperature increase during the period January-June. At the Tuotuohe site, variations of the daily maximum and minimum GT during winter are also consistent. However, for the whole-year period, the variations are well approximated by sine curves (Fig. 2). This indicates that although stochastic weather processes could affect the GT, its variations are mainly controlled by the solar radiation with a 1 year cycle.

For the D105 site, both the temperature decrease in early October and the increase in late April occur more quickly for daily maximum temperature than for daily minimum. In winter, especially from mid-October to mid-February, the maximum and minimum temperatures have approximately the same variation trends. From mid-February to the end of March, the daily maximum increased earlier than the daily minimum. From early May, the daily maximum GT increased quickly, with fluctuations, while the increase in daily minimum GT was relatively slow. As a result, the daily range of the GT is large during the summer.

At site D110, the GT pattern differs from that at more northerly sites. The variations of the daily maximum and minimum GT are inconsistent throughout the year, and do not correspond to a sine curve. The daily maximum and minimum GT fluctuate more in summer than in winter, and the daily maximum GT fluctuates more than the daily minimum. Especially at the end of September, the daily maximum temperature (DMAT) decreases more quickly than the daily minimum temperature (DMIT). Thus, the daily range of the GT (DRGT) decreases rapidly, after which the decrease of the DMAT and DMIT slows down. At this time the DRGT is already quite small. In early May, the DMAT increases rapidly, but the DMIT increases relatively slowly, so the DRGT increases again.

At sites WADD and Amdo, the variations of DMAT and DMIT are almost the same as at D110, but the variation trends of DMAT and DMIT at sites NODA and MS3637 are similar to those at site D105. The variations at site MS3608 are similar to those at Tuotuohe.

\subsection{Variation of the daily range of the ground temperature at different sites}

To examine the difference in temporal variation between DMAT and DMIT, the DRGT at $4 \mathrm{~cm}$ depth at different sites was calculated and is presented in Figure 3. The DRGT shows significant temporal and spatial variations. At site D66, it is larger, but fluctuates more, in summer than in winter. At Tuotuohe, the DRGT decreased from the end of August to the end of October, but increased throughout November, except for a sharp decrease around 26 November. It decreased again at the end of March and increased relatively quickly in mid-April. This demonstrates that the variation of the DRGT at Tuotuohe was less regular than at D66. 

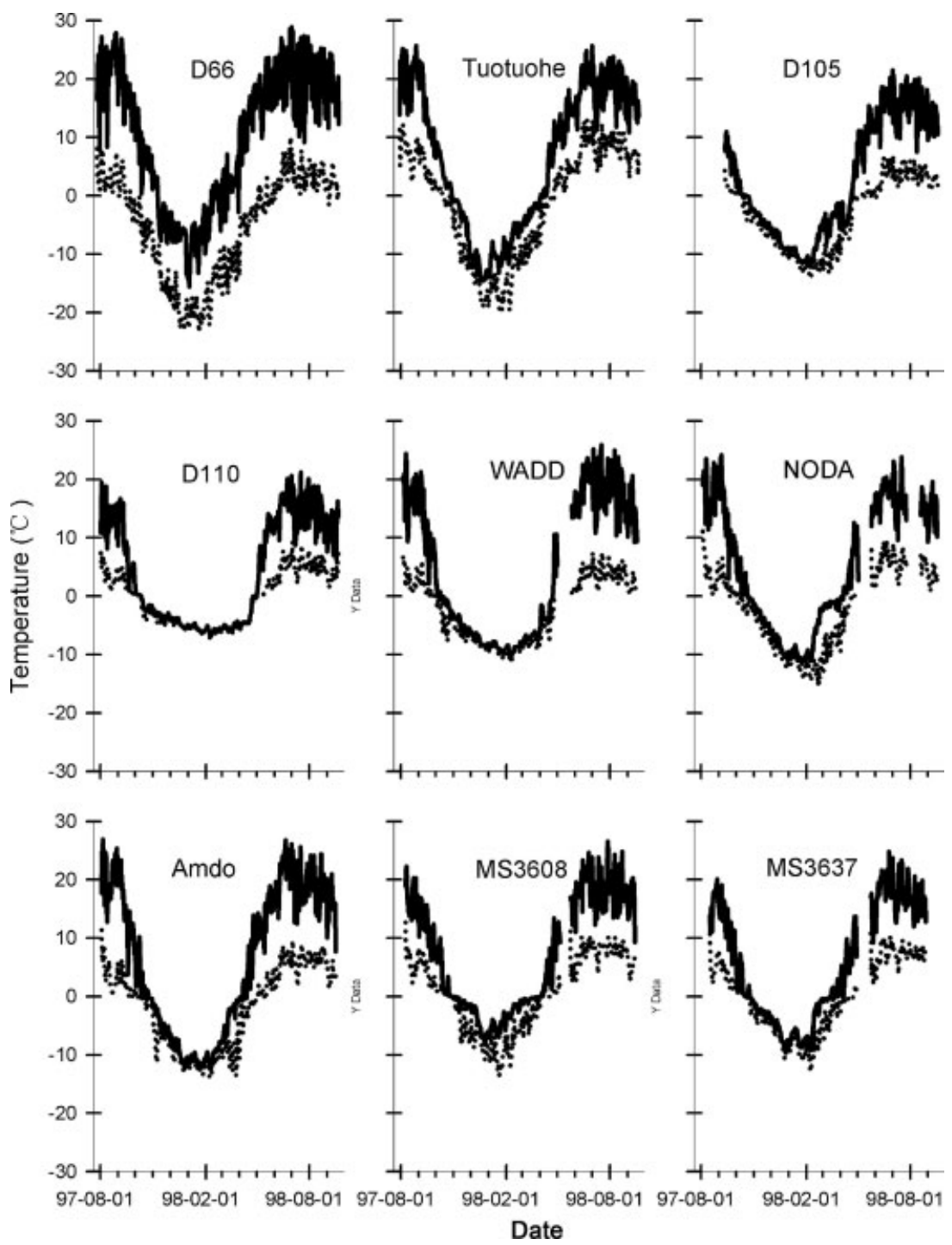

Fig. 2. The daily maximum and minimum ground temperature at $4 \mathrm{~cm}$ depth at different sites, 1 August 1997 to 1 October 1998 . The solid line is daily maximum temperature and the dotted line is daily minimum temperature. Dates are yy-mm-dd.

At site D105, the DRGT had already decreased by early October, then began to increase. In early November, it showed a small decrease that lasted for more than 3 months. From the end of February to early April it began increasing. At the end of April it increased quickly again. At site D110, the DRGT increased very rapidly from midSeptember, but became very small by the end of September. From the end of December 1997 to mid-April 1998, it was $<0.2^{\circ} \mathrm{C}$. It increased quickly after early May. The variation of DRGT at site WADD was similar to that at D110. However, the anomalies of DRGT at sites NODA, Amdo and MS3637 were not as significant as at D110. The DRGT began to increase in mid-March, suddenly decreased in early April, then increased but with variability. The trend in variability of the DRGT at site MS3608 was similar to that at Tuotuohe.

\section{DISCUSSION}

Our analysis shows that significant differences in temporal and spatial variations of the DMAT, DMIT and DRGT occurred from winter 1997 to early 1998 on the northern part of the Tibetan Plateau, as evident from records obtained at an array of sites located from south of the Kunlun Shan (D66) to south of Nagqu (MS3637). At site D110, the DRGT fluctuated within only $0.2^{\circ} \mathrm{C}$ from the end of December 1997 to mid-April 1998, but in the north, at site D66, it fluctuated from $5^{\circ} \mathrm{C}$ to $\sim 20^{\circ} \mathrm{C}$ at the same depth and during the same period. At the southernmost site (MS3637), the DRGT fluctuated about $1.0^{\circ} \mathrm{C}$ from mid-November to early February. From mid-February to mid-March, it increased, reaching $8.1^{\circ} \mathrm{C}$. An important question is why the variations of the DRGT in the Nagqu-Amdo region are different from those at site D66. In other words, why are the temporal and spatial distributions of the DRGT in the northern Tibetan Plateau in winter 1997/98 anomalous?

One first needs to know whether or not the above anomalies are related to the effect of the soil moisture content and freezing-thawing processes on the GT. The high soil-moisture content could result in a decrease in the DRGT, especially during the snowmelt period. This is easy to understand given that the heat capacity of water is relatively high, and the temperature decrease at night and increase during the day can be slow. This is especially true during the early winter and early summer when daytime temperature is not so high and night-time temperature not so low. If the 

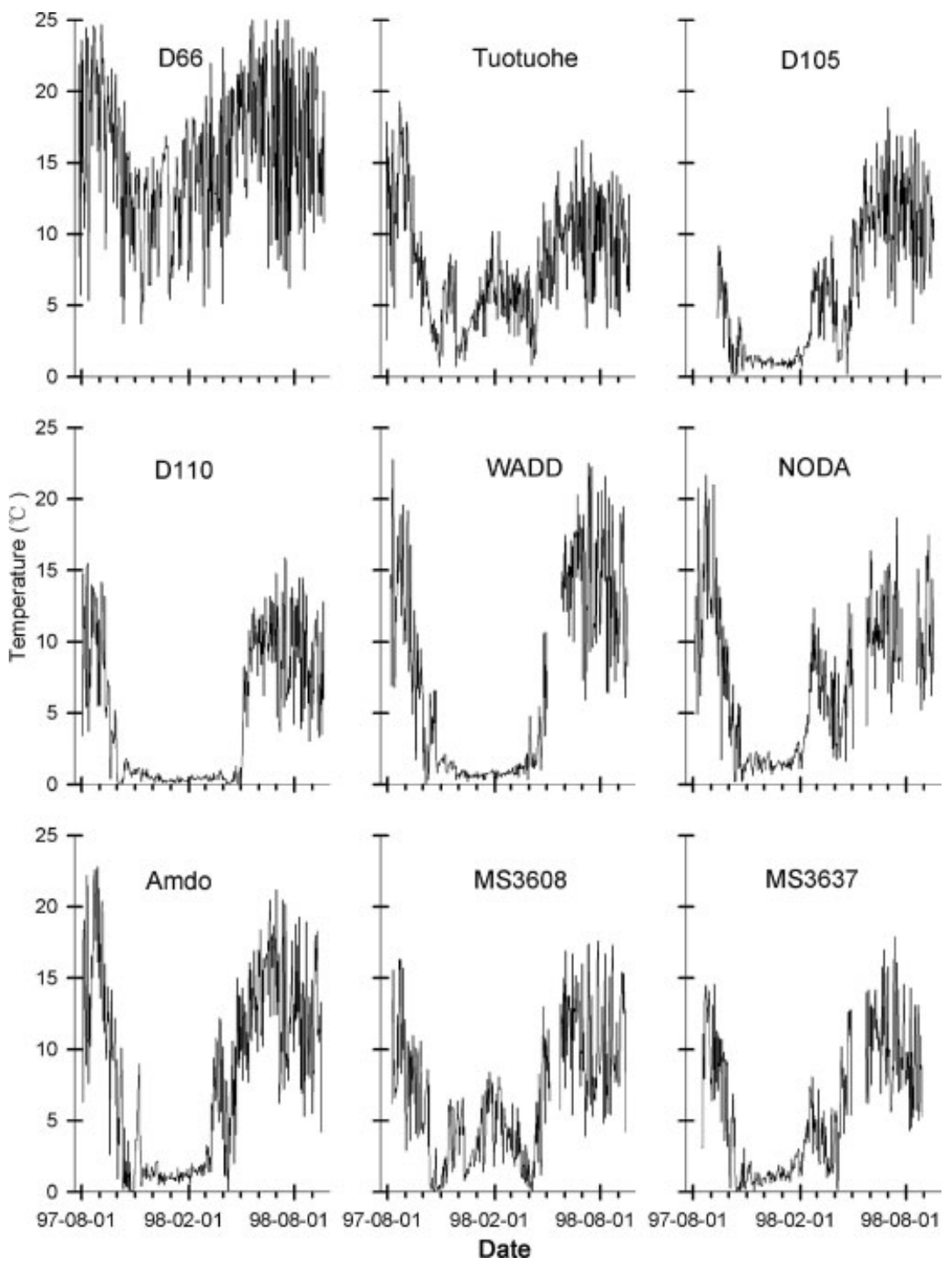

Fig. 3. The daily range of the ground temperature at $4 \mathrm{~cm}$ depth at different sites. Dates are $y y-m m-d d$.

water content near the GT measurement probe was quite high, such conditions would strongly affect the DMAT, DMIT and DRGT. We first examined site MS3608, located $50 \mathrm{~km}$ south of Nagqu. The DRGT was $1.3^{\circ} \mathrm{C}$ and $2{ }^{\circ} \mathrm{C}$ on 18 December 1997 and 14 January 1998 respectively, but the corresponding DMATs were $-5.4{ }^{\circ} \mathrm{C}$ and $-6.3^{\circ} \mathrm{C}$. Similar conditions also existed on 28 January 1998, when the DMAT was $-2.6^{\circ} \mathrm{C}$ and the DRGT reached $7.7^{\circ} \mathrm{C}$. However, the soil near the measurement probe did not thaw during this period. Even though the probe was completely surrounded by ice, its effect on the temperature was the same as when there is no ice. At the same site, when the soil freezes completely, the GT variation cannot be explained by variations in soil properties. This shows that the differences in DRGT can only be explained by weather processes and snow-cover variations. It is evident that weather processes could cause the DRGT to decrease, but they could not keep it very low for several months, and certainly could not cause it to fall below $0.2^{\circ} \mathrm{C}$ and then stay at that level for more than 4 months, as was the case at site D110. If the variation of DRGT at site D66 was due to weather processes, the variations of DRGT at D110 and other sites could only be caused by snow cover.
The above anomalous variations of DRGT can only be explained by the influence of the very heavy snowfall that occurred within the Amdo-Nagqu region in winter 1997/98. The snow cover thermally insulated the soil surface and modified the energy balance (Gosnold and others, 1997; Sokratov and Barry, 2002; Stieglitz and others, 2003; Bartlett and others, 2004; Smerdon and others, 2004; Pollack and others, 2005). On the one hand, when the ground is covered by snow it is decoupled from the air temperature that decreases the GT fluctuations. On the other hand, the heat conductivity of snow is small, making it difficult for solar radiation to pass into the soil during the daytime or to be emitted from the ground surface at night. This also causes GT fluctuation to decrease. Moreover, due to the high albedo of snow, less solar radiation is absorbed by the snowcover surface than by a bare surface. As a result, a relatively severe snow cover would significantly affect the DRGT. In other words, the variation in the DRGT, to some extent, would record the snow cover on the surface.

At present, there are only a few weather stations on the Tibetan Plateau. Most of them are located in river valleys and are not representative of the environmental conditions. Snow cover in the Northern Hemisphere is monitored 
mainly by means of satellite remote sensing, but the resolution of remotely sensed data is usually low. The SMTMS installed by GAME-Tibet on the northern Tibetan Plateau can be used to evaluate snow cover during winter 1997/98. Although no empirical snow-depth observations were performed, the variations of the DRGT are considered to provide a qualitative reflection of the severity of the heavy snow at different sites on the northern Tibetan Plateau.

\section{ACKNOWLEDGEMENTS}

We thank the two referees for valuable and constructive criticism. We also thank N. Shiklomanov at University of Delaware for improving the English. This research was jointly supported by the National Basic Research program of China (2005CB422004), the National Natural Science Foundation (40201012, 40571036), the Innovation Group Fund (40121101), the Key Projects of CAS (Chinese Academy of Sciences; KZCX2-SW-118), the Century Program of the Chinese Academy of Sciences (2004401), and the Talent Program of the Cold and Arid Regions Environmental and Engineering Research Institute, CAS. We thank all the colleagues who helped so much with the fieldwork.

\section{REFERENCES}

Barnett, T.P., L. Dümenil, U. Schlese, E. Roeckner and M. Latif. 1989. The effect of Eurasian snow cover on regional and global climate variations. J. Atmos. Sci., 46(5), 661-685.

Bartlett, M.G., D.S. Chapman and R.N. Harris. 2004. Snow and ground temperature record of climate change. J. Geophys. Res., 109(F4), F04008. (10.1029/2004JF000224.)

Chen, L. 2001. The role of the anomalous snow cover over the Qinghai-Xizang Plateau and ENSO in the Great Floods of 1998 in the Changjiang River Valley. Chinese J. Atmos. Sci., 25(2), 184-192.

Gosnold, W.D., P.E. Todhunter and W. Schmidt. 1997. The borehole temperature record of climate warming in the midcontinent of North America. Global Planet. Change, 15, 33-45.

Hahn, D.G. and S. Manabe. 1975. The role of mountain in the South Asia monsoon. J. Atmos. Sci., 32, 1515-1541.

Kuo, H.L. and Y.F. Qian. 1982. Numerical simulation of the development of mean monsoon circulation in July. Mon. Weather Rev., 110, 1879-1897.
National Climate Centre (NCC) of China. 1998. The 1998 severe floods in China and the climate anomalies. Beijing, China Meteorological Press. [In Chinese.]

Pollack, H.N. and J.E. Smerdon. 2004. Borehole climate reconstructions: spatial structure and hemispheric averages. J. Geophys. Res., 109(D11), D11106. (10.1029/2003JD004163.)

Pollack, H.N., J.E. Smerdon and P.E. van Keken. 2005. Variable seasonal coupling between air and ground temperatures: a simple representation in terms of subsurface thermal diffusivity. Geophys. Res. Lett., 32(L15), L15405. (10.1029/ 2005GL023869.)

Qian, Y., H. Yian, Q. Wang and A. Wang. 1988. Numerical studies of topographic effects on planetary atmosphere. Beijing, Science Press. [In Chinese.]

Qian, Y.F., S.Y. Wang and H. Shao. 2001. A possible mechanism effecting the earlier onset of southwesterly monsoon in the South China Sea compared to the Indian monsoon. Meteorol. Atmos. Phys., 76(1-4), 237-249.

Qian, Y.F., Y.Q. Zheng, Y. Zhang and M.Q. Miao. 2003. Responses of China's summer monsoon climate to snow anomaly over the Tibetan Plateau. Int. J. Climatol., 23(6), 593-613.

Smerdon, J.E. and 6 others. 2004. Air-ground temperature coupling and subsurface propagation of annual temperature signals. J. Geophys. Res., 109(21), D21107. (10.1029/2004JD005056.)

Sokratov, S.A. and R.G. Barry. 2002. Intraseasonal variation in the thermoinsulation effect of snow cover on soil temperatures and energy balance. J. Geophys. Res., 107(D10), 4093. (10.1029/ 2001JD000489.

Stieglitz, M.D., S.J. Romanovsky and T.E. Osterkamp. 2003. The role of snow cover in the warming of Arctic permafrost. Geophys. Res. Lett., 30(13), 1721. (10.1029/2003GL017337.)

Vernekar, A.D., J. Zhou and J. Shukla. 1995. The effect of Eurasian snow cover on the Indian Monsoon. J. Climate, 8(2), 248-266.

Wang, A.Y. 1984. Numerical simulations of effects of the East Asian heating field in early summer on mean atmospheric circulation. In Collected papers on the Tibetan Plateau Meteorological Scientific Experiment (II). Beijing, Science Press, 273-280. [In Chinese.]

Webster, P.J. and 6 others. 1998. Monsoons: processes, predictability, and the prospects for prediction. J. Geophys. Res., 103(C7), 14,451-14,510.

Wu, G.X. and Y.S. Zhang. 1998. The thermal and mechanical forcing of the Tibetan Plateau and the onset of Asian monsoon. Part I. Site of the onset. Sci. Atmos. Sin., 22, 825-837.

Yasunari, T., A. Kitoh and T. Tokioka. 1991. Local and remote responses to excessive snow mass over Eurasia appearing in the northern spring and summer climate - a study with the MRIGCM. J. Meteorol. Soc. Jpn, 69, 473-487. 